\title{
Physical Exercise in Post-Polio Syndrome: Highlights
} \author{
Orsini $^{4}$ \\ ${ }^{1}$ Rio de Janeiro Federal Institute of Education, Science and Technology (IFRJ), Rio de Janeiro, Brazil \\ ${ }^{2}$ Faculty of Medicine of the Federal University of Rio de Janeiro Rio de Janeiro (UFRJ), Brazil \\ ${ }^{3}$ Federal University of São Paulo, Department of Neurology, São Paulo SP, Brazil \\ ${ }^{4}$ University of Vassouras, Rio de Janeiro, Brazil
}

Mauricio De Sant Anna*1, Tiago Batista Da Costa Xavierr', Carlos Henrique Melo Reis ${ }^{2}$, Acary SB Oliveira ${ }^{3}$ and Marco

Received: 眥: October 15, 2018; Published: 踾: October 26, 2018

*Corresponding author: Mauricio de Sant Anna, Instituto Federal de Educação, Ciência e Tecnologia do Rio de Janeiro, Campus Realengo, Rua Professor Carlos Wenceslau (antiga Rua Oliveira Braga), 343, Realengo - Rio de Janeiro, Brazil

\section{Opinion}

Post-poliomyelitis syndrome (PPS) is an entity characterized by a new episode of muscle weakness and abnormal fatigue in individuals affected by acute poliomyelitis (PAA) years before [1]. The diagnosis of PPS is based on the fulfillment of the following criteria:

a) Confirmed history of paralytic poliomyelitis;

b) Evidence of motor neuron injury inferior to neurological examination, with signs of residual weakness, atrophy, decrease or abolition of tendon reflexes, in the absence of sensitivity impairment;

c) Partial or complete neurological recovery period after acute insult, followed by neurological and functional stability for at least 15 years;

d) Worsening or worsening of abnormal weakness or fatigue, with or without generalized fatigue, muscular atrophy or muscle and joint pain;

e) Symptoms usually begin gradually, although they may be sudden, and should persist for at least one year. Absence of another diagnosis that may explain the symptoms [2].

Physical rehabilitation in patients with PPS can be compounded by performing resistance exercises (strength training), aerobic exercises, stretching exercises, energy conservation techniques and when necessary the prescription of orthoses [3-6].

There is a controversy regarding the prescription of therapeutic exercises for the patient with PPS. This disagreement arises from the fact that some studies have demonstrated the onset of muscle weakness due to overtraining. This is a justifiable fact since we are recruiting already staggering neuromuscular units as a result of PAA and that the new skeletal muscle weakness in PPS can be triggered by disuse, over training or by a combination of both. On the other hand other studies have demonstrated that the regular practice of exercise in patients with SPP can increase muscular endurance, besides bringing benefits to the cardiovascular system [5,7]. In an elegant review carried out by Tiffreau et al, 14 works related to physical exercise in SPP were selected, two of which involved exclusively aerobic training, seven on resistance training, two on hydrotherapy, one on concurrent training (aerobic and resisted in the same therapeutic session) and one where exercise prescription was performed according to subjects' daily observation.

It was observed that aerobic exercises at submaximal intensity and resistance exercises at low intensity were able to promote improvements in cardiorespiratory function and muscle strength, in addition to describing that the Aquatic therapy activity has a positive impact on pain and muscle function. In patients with severe fatigue. It should be noted that the prescription of aerobic exercise was performed after evaluation using ergospirometry and resisted exercise was prescribed after isokinetic evaluation, which makes the intensity of the prescribed activity with greater reliability. We could not fail to mention that SPP can affect the ventilatory muscles, and just as in the peripheral musculature the muscles of respiration are affected in a non symmetrical way triggered several forms of alteration [8]. Shoseyov et al. [9] demonstrated that in their study, patients with PPS when compared to a control group did not present differences regarding lung function, strength and resistance of the respiratory muscles in resting condition, but when submitted to a higher ventilatory stress through the test of maximum voluntary ventilation observed a significant reduction in inspiratory muscle strength. 
It should be noted that in exercise the peripheral musculature competes for blood flow to the respiratory muscles [10] for this reason to reduce the possibility of overuse, perhaps the performance of a low intensity training specifically targeted to the ventilatory muscles and that has already proved efficient in other [11-13] could improve exercise tolerance and quality of life in patients with PPS, but the literature is still unclear regarding respiratory muscle training for this population and variables such as frequency, intensity, duration and load deserve further clarification. Another strategy that has proven effective in other populations to increase exercise tolerance and that could reduce overuse is the use of noninvasive positive pressure ventilation during exercise [14-16], but which requires further study in patients with PPS.

\section{Conclusion}

In conclusion, we believe that physical exercise in patients with post-polio syndrome can be safely performed, without promoting overuse, provided it is prescribed individually and by specialist, in addition, new strategies such as inspiratory muscle training and pressure positive patients during exercise should be explored in new investigations as they have the potential to reduce overuse in this population.

\section{References}

1. Neves MAO, Mello MP, Reis JPB, Rocha J, Rei AM, et al. (2007) Postpolio symptoms and the motor rehabilitation process: case report. Rev Neurocienc 15(4): 321-325.

2. Orsini M, Freitas MRG, Reis CHM, Mello M, Porto F, et al. (2010) Neurological Rehabilitation Guideline for Post-Polio Syndrome: Interdisciplinary Approach. Rev Neurocienc 18(2): 204-213.

3. Gross MT, Schuch CP (1989) Exercise Programs for Patients with PostPolio Syndrome: A Case Report Phys Ther 69(1): 72-76.

4. Oncu J, Durmaz B, Karapolat H (2009) Short-term effects of aerobic exercise on functional capacity, fatigue, and quality of life in patients with post-polio syndrome. Clin Rehabil 23(2): 155-163.

5. Orsini M, Lopes AJ, Guimarães FS, Freitas MR, Nascimento OJ, et al. (2016) Currents issues in cardiorespiratory care of patients with postpolio syndrome. Arq Neuropsiquiatr 74(7): 574-579.

\section{ISSN: 2574-1241}

DOI: 10.26717/BJSTR.2018.10.001953

Mauricio de Sant Anna. Biomed J Sci \& Tech Res

This work is licensed under Creative

Commons Attribution 4.0 License

Submission Link: https://biomedres.us/submit-manuscript.php
6. Lo JK, Robinson LR (2018) Post-polio syndrome and the late effects of poliomyelitis: Part 2. treatment, management, and prognosis. Muscle Nerve.

7. Tiffreau V, Rapin A, Serafi R, Percebois Macadré L, Supper C, et al. (2010) Post-polio syndrome and rehabilitation. Ann Phys Rehabil Med 53(1): 42-50.

8. Laghi F, Tobin MJ (2003) Disorders of the Respiratory Muscles. Am J Respir Crit Care Med 168(1): 10-48.

9. Shoseyov D, Cohen Kaufman T, Schwartz I, Portnoy S (2017) Comparison of activity and fatigue of the respiratory muscles and pulmonary characteristics between post-polio patients and controls: a pilot study. Plos one 12(7): e0182036.

10. Dempsey JA, Romer L, Rodman J, Miller J, Smith C (2006) Consequences of exercise-induced respiratory muscle work. Respir Physiol Neurobiol 151(2-3): 242-250.

11. Ferreira GD, Costa AC, Plentz RD, Coronel CC, Sbruzzi G (2016) Respiratory training improved ventilatory function and respiratory muscle strength in patients with multiple sclerosis and lateral amyotrophic sclerosis: systematic review and meta-analysis. Physiotherapy 102(3): 221-228.

12. Beaumont M, Forget P, Couturaud F, Reychler G (2018) Effects of inspiratory muscle training in COPD patients: A systematic review and meta-analysis. Clin Respir J 12(7): 2178-2188.

13. Sadek Z, Salami A, Joumaa WH, Awada C, Ahmaidi S, et al. (2018) Best mode of inspiratory muscle training in heart failure patients: a systematic review and meta-analysis. Eur J Prev Cardiol 3: 1691-1701.

14. De Sant Anna M, Mafra Moreno A, Da Silva Soares PP (2013) The effects of positive airway pressure on cardiovascular responses, perceived effort and time to exhaustion during high-intensity exercise in healthy subjects. J Sports Med Phys Fitness 53(6): 604-611.

15. Kamisaka K, Sakui D, Hagiwara Y Kamiya K, Adachi T, et al. (2016) Mechanical ventilatory assistance may reduce dyspnea during walking especially in patients with impaired cardiopulmonary function early after cardiovascular surgery. J Cardiol 67(6): 560-566.

16. Feldman RM, Soskolne CL (1987) The use of nonfatiguing strengthening exercises in post-polio syndrome. Birth Defects Orig Artic Ser 23(4): 335-341. 